\title{
Relações entre poder público e sociedade na gestão de residuos sólidos de um municipio de minas gerais: uma análise sob o enfoque das abordagens da administração pública
}

\author{
Relations between public authorities and society in solid waste \\ management of a city of minas: an analysis of approaches in the focus \\ of public administration
}

\section{Resumo}

O objetivo desse artigo é analisar o conteúdo do discurso dos atores sociais envolvidos na gestão de resíduos sólidos de um município mineiro, verificar as relações existentes entre eles e relacioná-las com a administração pública. Optouse por uma pesquisa qualitativa. Utilizou-se de um roteiro semi-estruturado e aplicou-se a técnica de análise do conteúdo. As entrevistas foram relacionadas com as abordagens da administração pública. Constatou-se que nenhuma abordagem apareceu nas relações na sua forma pura, apresentando-se combinada umas com as outras. Verificou-se nas relações a existência das abordagens patrimonialista, burocrática, gerencial, societal e sistêmica.

Palavras-chave: Abordagens, Administração Pública, Gestão de Resíduos Sólidos.

\begin{abstract}
The purpose of this article is to analyze the inside of the discourse of social actors involved in the solid waste management from town of the Minas Gerais, ascertain the relationship between them with the approaches of public administration. We opted for a qualitative research. We used a semi-structured and applied the technique of content analysis methodology. The interviews were related to the approaches of public administration. It was found that no approach appeared in relations in pure form, presenting combined with each other. It was found in the existence of relations approaches patrimonial, bureaucratic, managerial, societal and systemic.
\end{abstract}

Keyword: Approaches, Public Administration, Solid Waste Management.

1 livia.padua@ig.com.br, Brasil. Professora Titular do Centro Federal de Educação Tecnológica de Minas Gerais CEFET/MG. Doutoranda em Administração na Universidade Federal de Lavras - UFLA. Caixa- Postal 3037 - CEP: 37200 000 - Lavras, MG - Brasil.

2jrobpereira25@yahoo.com.br, Brasil. Professor Associado da Universidade Federal de Lavras - UFLA. Doutor em Sociologia pela Universidade de Brasília - UNB. Caixa- Postal 3037 - CEP: 37200-000 - Lavras, MG - Brasil.

Recebido em 19.09.2012

Aprovado em 30.05.2014

Revista Administração em Diálogo

ISSN 2178-0080

Programa de Estudos Pós-Graduados em Administração

Pontifícia Universidade Católica de São Paulo 


\section{Introdução}

O objetivo desse artigo é analisar o conteúdo do discurso dos atores sociais envolvidos na gestão de resíduos sólidos de um município mineiro de modo a verificar as relações existentes entre eles e relacioná-las com as abordagens da administração pública. O artigo visa compreender melhor a administração pública contemporânea e as tendências das relações entre o poder público e sociedade. Como objetivo específico o artigo buscou descrever as principais características das abordagens da administração pública: patrimonialista, burocrática, gerencial, societal e sistêmica.

A teoria da abordagem da administração pública explica as relações e articulações estabelecidas entre o poder público e a sociedade no gerenciamento dos resíduos sólidos do município localizado em Minas Gerais. Por isso, nessa pesquisa procurou identificar a abordagem predominante nas relações dos atores sociais envolvidos na gestão de resíduos sólidos. Os atores sociais são funcionários públicos, políticos, promotor, professores, empreendedores, trabalhadores da iniciativa privada, catadores de materiais recicláveis, representantes de entidades ambientais e sociais. $\mathrm{O}$ estudo instigou reflexões sobre as relações do poder público e sociedade, despertando para algumas questões: Existe uma abordagem de administração pública predominante nas relações dos atores sociais envolvidos na gestão de resíduos sólidos do município em estudo? Uma abordagem de administração pública exclui a outra? Quais são as características das relações do poder público e sociedade em cada uma das abordagens da administração pública (patrimonialista, burocrática, gerencial, societal e sistêmica)?

Como suporte teórico, o artigo fundamenta-se nos conceitos das abordagens patrimonialistas, burocrática, gerencial, societal e sistêmica. Estas abordagens da administração pública são essenciais para compreender a relação dos atores sociais envolvidos na gestão de resíduos sólidos de um município de Minas Gerais.

Quanto aos procedimentos metodológicos utilizou-se da pesquisa qualitativa. Como método de análise empírica recorreu-se ao estudo de caso. Ressalta-se que o estudo foi realizado por meio de aplicação de um roteiro semi-estruturado de entrevista que foram transcritas e relacionadas com as abordagens da administração pública. Para a realização das entrevistas foram elaborados roteiros constituídos por três grupos de perguntas (categorias): (I) sobre as relações estabelecidas entre os atores sociais; (2) 
sobre o funcionamento e o papel dos atores sociais na gestão dos resíduos sólidos do município em estudo; (3) sobre as práticas que caracterizam as abordagens da administração pública na gestão de resíduos sólidos. Aplicou-se a técnica de análise de conteúdo (BARDIN, 2009). Foram entrevistados 48 atores sociais envolvidos na gestão de resíduos sólidos de um município de Minas Gerais. Os entrevistados foram categorizados em três setores: Setor Público (SPu), Setor Privado (SPr) e Terceiro Setor (TS). Além disso, foram coletados dados por meio das seguintes técnicas: pesquisa documental, observação e anotações de campo.

Os resultados explicitaram que nenhuma abordagem da administração pública apareceu nas relações na sua forma pura, apresentando-se combinada umas com as outras. Verificou-se que as relações do poder público e sociedade, no gerenciamento dos resíduos sólidos de um município de Minas Gerias, apresentaram evidências das abordagens patrimonialista, burocrática, gerencial, societal e sistêmica. Os fenômenos estudados, as relações dos atores sociais envolvidos em uma gestão de resíduos sólidos municipal, são influenciados pelos condicionamentos culturais, históricos, políticos e sociais do município, além do amplo contexto que está inserido. Esse conjunto de condicionamentos admitiu um cenário com diversas abordagens da administração pública nas relações do poder público e sociedade. Percebe-se um processo dinâmico, permanente, conflitivo e inacabado. Compreende-se que os atores sociais necessitam romper com relações patrimonialistas, ampliar espaços democráticos, fazer uso de práticas que condizem com a sua realidade e criar possibilidades de obter uma maior sinergia.

\section{Fundamentação Teórica}

As abordagens da administração pública

O cenário brasileiro possui evidências das abordagens patrimonialista, burocrática, gerencial, societal e sistêmico, que se confirma com as publicações das pesquisas pelos autores Rezende (2OII), Freitas (2009), Araújo (2OII), Paes de Paula (2005), Klering, Porsse e Guadagnin (2010), Filippim e Rossetto (2006). O patrimonialismo, a burocracia, o gerencialismo são considerados abordagens básicas na 
literatura; o societal é uma abordagem nova, mas que já foi institucionalizada no meio acadêmico. A abordagem sistêmica é incipiente na literatura, porém, ainda não foi institucionalizada no meio acadêmico. Diversos autores, como Ackroyd, Kirkpatrick e Walker (2007); Hansen (2OII); Moynihan (2006); Paes de Paula (2005); Klering, Porsse e Guadagnin (20IO) defendem que a administração pública tem sofrido mudanças e mencionam modelos e tendências para uma administração mais participativa, eficiente e integrada em rede.

Abordagem patrimonialista

O Patrimonialismo foi herdado de Portugal desde o início da colonização brasileira. Na abordagem patrimonialista, os governantes não devem satisfação aos governados e não há distinção clara acerca daquilo que pertence ao Estado e ao próprio soberano (FAORO, 2OOI)

O cenário associado ao patrimonialismo, segundo Martins (I997) é marcado pelas elites improdutivas, formada por antigos nobres, que obtém privilégios e vantagens em razão das relações de parentesco ou de políticas existentes com o governante.

Bresser-Pereira (2005) explica que o patrimonialismo caracteriza-se pela presença do clientelismo, nepotismo e favoritismo. O patrimonialismo contempla um modo personalista de poder, pela ausência de uma esfera pública, pela lógica subjetiva do sistema jurídico, pela irracionalidade fiscal e pela tendência à corrupção. Skarica (2OI2) explica que a administração pública é fortemente influenciada pelo legado histórico e pelos sistemas políticos.

\section{Abordagem burocrática}

A teoria da burocracia foi formalizada pelo sociólogo Max Weber. Para Weber (2005), a burocracia era a forma mais eficiente de uma organização. Na concepção de Weber (2005), a burocracia fundamentava-se no poder da dominação racional legal, ou seja, nos regulamento e leis que se aplica a toda a população.

No Brasil, no período de ascensão de Getúlio Vargas, na década de ı93o, tem-se uma tentativa de profissionalizar a administração pública com a criação do Departamento de Administração do Serviço Público - DASP. Por intermédio do DASP, promovem-se a 
estruturação básica do aparelho administrativo instituindo o concurso público, as regras para admissão e treinamentos dos servidores. Esta fase ficou conhecida como Reforma Burocrática e foi a primeira tentativa de reformar a administração pública, ou seja, de eliminar práticas cujas aplicações se demonstravam esgotadas (CAPOBIANGO et al., 2ОIO).

A burocracia, segundo Bresser-Pereira (2005), distinguia claramente o público e o privado; e separava o político do administrador. O modelo burocrático orientava-se pelas idéias de profissionalização, carreira, hierarquia funcional, legalismo, formalismo, controle e impessoalidade.

A disfunção da burocracia pode ser observada quando o controle transforma em um verdadeiro fim do Estado e não em um simples meio de atingir seus objetivos. Nessa situação, perde-se a noção da missão básica do Estado que é a de servir a sociedade. Merton (I970) explica que as disfunções da burocracia podem tornar a administração pública ineficiente. A superioridade técnica sobre as demais formas, a supervalorização de regulamentos, a resistência à mudança, as limitações das interações organizaçãousuário, a formalidade excessiva e a hierarquização das decisões são disfunções da burocracia, que segundo Bresser-Pereira (2005) transforma a administração pública em lenta, cara e com deficiência no atendimento aos cidadãos.

\section{Abordagem gerencial}

A administração pública gerencial iniciou-se nos anos de I980 devido ao movimento internacional que visava à reforma do Estado. Os principais exemplos de implantação dessa abordagem são os governos de Ronald Regan (I980-I988) nos Estados Unidos e Margareth Thatcher (I979-I987) na Inglaterra (PAES DE PAULA, 2005). No Brasil, a Reforma Gerencial do Estado iniciou-se na década noventa no governo Fernando Henrique Cardoso.

A abordagem gerencial brasileira refere-se a uma adaptação do Estado para poder enfrentar os desafios de um mundo contemporâneo, de forma que o governo concentre-se na prestação de serviços básicos e exclusivos à população, e transfira à sociedade, à iniciativa privada a produção de bens e serviços que os mesmos possam desenvolver com eficiência e com menor custo para o consumidor (CARDOSO, 2005). 
Essa abordagem é caracterizada por adotar práticas gerenciais provenientes do setor privado e transformar o governo em um "Estado empreendedor" (OSBORNE; GAEBLER, r992).

Para Bresser-Pereira (2005) e Paes de Paula (2005), a abordagem gerencial abrange os seguintes aspectos: introdução de conceitos de avaliação de desempenho, eficiência, transparência ao planejamento e ações da administração pública; competição entre organizações públicas e entre organizações públicas e privadas; orientação da gestão por resultados e avaliação de desempenho centrada nos outputs. Além desses aspectos, Osborne e Gaebler (I992) mencionam como característica dessa abordagem: a descentralização do poder; o estabelecimento de mecanismo de mercado; e a construção de parcerias com o setor privado e as organizações sociais.

\section{Abordagem societal}

A abordagem societal no Brasil, segundo Paes de Paula (2005), teve a sua origem nos movimentos sociais iniciados na década de ı960 e ı970. No entanto, as práticas dessa abordagem surgiram no final da década de 1980 com a apresentação de fóruns temáticos, conselhos gestores de políticas públicas e orçamento participativo. Freitas Jr. (2009, p.33) descreve que os fóruns temáticos caracterizam-se pela "participação popular na discussão política, por meio da troca livre e aberta de idéias”. Os conselhos gestores de políticas públicas "pela inserção da sociedade na formulação e na implementação de políticas públicas”, aproximando de um papel deliberativo. Já os orçamentos participativos referem-se à "participação popular na definição de prioridades e destinação de recursos do orçamento municipal”.

A concepção dessa abordagem está na participação da sociedade nos assuntos políticos do país e na reivindicação da cidadania (PAES DE PAULA, 2005). Tenório e Rozenberg (I997) explicam que a participação faz parte da vida de todos os indivíduos. Ao longo da vida, por seu próprio desejo ou não, os indivíduos são levados a participar de grupos e atividades conjuntas. Para os autores, a participação possibilita a abertura de espaços de discussões, elaboração de estratégias de ação e o estabelecimento de diálogo com o poder público. Além de um maior controle social sobre as ações estatais e desmonopolização da formulação e implementação das ações públicas (PAES DE 
PAULA, 2005). Tenório (I990) destaca que o grau de conhecimento entre os participantes, não deve ser usado para estabelecer relações de poder sobre os demais que não detém esse saber. Numa relação coletiva, o conhecimento deve ser usado como apoio às discussões, de maneira que seja compartilhado com o grupo, inexistindo os "donos da verdade".

A administração pública societal, conforme Paes de Paula (2005) trata-se de uma participação efetiva e não de uma participação no nível do discurso. Na abordagem societal o indivíduo participa decidindo seu destino como cidadão, definindo a sua agenda política e participando da formulação e implementação das políticas públicas. $\mathrm{O}$ paradigma de gestão é social, enfatizando o desenvolvimento autossustentável, incluindo questões culturais e participativas.

\section{Abordagem sistêmica}

O "Estado em rede" é uma nova abordagem ainda não institucionalizada pela academia e surge com o objetivo de se adequar aos desafios contemporâneos (KLERING; PORSSE; GUADAGNIN, 2OIO). A abordagem em questão refere-se à articulação do Estado com diversos atores (entre empresas, organização da sociedade civil e o próprio poder público) constituindo as denominadas redes de políticas públicas.

Castells (I999) afirma que estrutura em redes é um sistema aberto, dinâmico, suscetível de inovação, flexível e que se modifica a medida que for necessário. A formação de redes organizacionais, segundo Nascimento e Ckgnazaroff (2007) é bastante utilizada no mundo empresarial e pode ser vista como uma alternativa também para o setor público. Os autores explanam que as redes de políticas públicas ocorrem através de interação entre diversos atores em que o Estado exerce a posição de igualdade em relação aos mesmos. As redes definem os papéis a ser desempenhadas pelos atores, compartilham conhecimento e tecnologias criando uma sinergia de forma a solucionar problemas de domínio público.

As redes na administração pública englobam a preocupação em obter a eficiência na prestação de serviços públicos estabelecendo uma relação com o sentido da prática do gerencialismo orientada a resultados, de acordo com os autores Berry et al. (2004). O modelo em rede apresenta uma interação multidimensional, envolvendo o humano-social, 
econômico, científico-tecnológico, ambiental sustentável, político-institucional e democrático.

Segundo Klering, Porsse e Guadagnin (2OIO), a administração pública com enfoque sistêmico no Brasil teve suas primeiras experiências a partir da década de ı990, com destaque dos programas federais desenvolvidos pelos três níveis de governo e diversos atores, como o programa do SUS (Sistema Único de Saúde); do REDESAN (Rede Integrada de Equipamentos Públicos de Segurança Alimentar e Nutricional do Ministério de Desenvolvimento Social e Combate à Fome); e do Território de Cidadania. A abordagem sistêmica tem os seguintes aspectos: é adaptativa; procura se ajustar constantemente; é flexível; possui multidimensionalidade e multiníveis; e reconhece o sistema como contingencial (o direcionamento das atividades depende das contingências que ocorrem).

A abordagem sistêmica abrange a governança pública, que segundo Snijkers (2005) implica na colaboração do governo e cidadãos em todas as fases das políticas públicas: elaboração, implementação, controle e avaliação das políticas. Pina, Torres e Acerete (2007) explicam que nesse contexto, os cidadãos não estão subordinados ao governo. Segundo os autores os cidadãos e o governo estão em uma relação de igualdade, uma vez que são colocados como parceiros.

Para uma melhor compreensão, segue o Quadro I constando as principais características das abordagens da administração pública.

Quadro I - Características das abordagens da administração pública

\begin{tabular}{|c|c|}
\hline Abordagens & Características \\
\hline Patrimonialista & $\begin{array}{l}\text { - Lealdade à pessoa que governa; } \\
\text { - Favoritismo e critérios pessoais na distribuição de cargos e benesses públicas; } \\
\text { - Personalismo: predominância da vontade do governante; } \\
\text { - Clientelismo, nepotismo e assistencialismo mantendo a população dependente de ações } \\
\text { esporádicas; } \\
\text { - Improviso: ação realizada sem planejamento prévio. }\end{array}$ \\
\hline Burocrático & $\begin{array}{l}\text { - Centralização da tomada de decisão e dos controles; } \\
\text { - Padronização dos processos e procedimentos; } \\
\text { - Formalismo: ação mediante normas pré-estabelecidas; } \\
\text { - Impessoalidade: tratamento igual para todos; } \\
\text { - Hierarquização: divisão e escalonamento do trabalho; } \\
\text { - Legalismo: obediência restrita às leis e aos estatutos; } \\
\text { - Disciplina, foco nos controles e na especialização do serviço; } \\
\text { - Departamentalização rígida; } \\
\text { - Eficiência: fazer mais com menos e fazer o que se espera que se faça naquela função. }\end{array}$ \\
\hline
\end{tabular}




\begin{tabular}{|c|c|}
\hline Gerencial & $\begin{array}{l}\text { - Descentralização da administração pública, promovendo maior autonomia; } \\
\text { - Modernização da estrutura organizacional: institucionalização das agências reguladoras e das } \\
\text { organizações sociais; } \\
\text { - Adoção de práticas de gestão do setor privado; } \\
\text { - Estratégias neoliberais de estabilização econômica; } \\
\text { - Participação no nível do discurso, pois, o processo decisório é centralizado; } \\
\text { - Foco na gestão por resultados e avaliação de desempenho centrada nos outputs; } \\
\text { - Valorização da eficiência e da qualidade dos serviços públicos; } \\
\text { - Gestão responsável por recursos públicos; } \\
\text { - Gestão de pessoas e do conhecimento da organização pública; } \\
\text { - Transparência ao planejamento e ações da administração pública; } \\
\text { - Inovação: busca constante de soluções inovadoras; } \\
\text { - Competitividade e eficácia: fazer aquilo que atenda aos objetivos da organização pública e do } \\
\text { - atendimento ao cidadão; } \\
\text { - Dimensão econômico-financeira e institucional-administrativa. }\end{array}$ \\
\hline Societal & $\begin{array}{l}\text { - Participação efetiva, enfatizando a elaboração de estruturas e canais que viabilizem a } \\
\text { - } \text { participação popular; } \\
\text { - Ética, ênacaño dos conselhos gestores de políticas públicas e fóruns temáticos; } \\
\text { - A gestão é compreendida como uma ação político-deliberativa, na qual o indivíduo participa } \\
\text { decidindo seu destino como cidadão; } \\
\text { - A autodeterminação se dá pela lógica da democracia e não pela lógica do mercado; } \\
\text { - Dimensão sociopolítica e democrática; } \\
\text { - Criação de instrumentos que possibilite um maior controle social sobre as açães estatais; } \\
\text { - Participação popular na definição da agenda política, na formulação e na implementação das } \\
\text { ações públicas. }\end{array}$ \\
\hline Sistêmico & $\begin{array}{l}\text { - Desenvolvimento de programas multiníveis e multiesferas do governo; } \\
\text { - Programas desenvolvidos ao mesmo tempo por diferentes atores governamentais e sociais, } \\
\text { visando atingir maior sinergia e efetividade das ações; } \\
\text { - Arranjos em rede: integração de projetos, de ações, de instituições e de pessoas; } \\
\text { - Estabelecimento de estrutura em rede para geração de resultados de desenvolvimento; } \\
\text { - Adaptativo, em contínuo ajustamento e com desenhos de cargos mutáveis; } \\
\text { - Multidimensional: humano-social, econômico, científico-tecnológico, ambiental sustentável, } \\
\text { - político-institucional, democrático, global e local; } \\
\text { - Busca solucionar conflitos através da negociação; } \\
\text { - A base do relacionamento é a confiança e a responsabilidade é compartilhada; } \\
\text { - Autonomia das partes, ação descentralizada, ênfase nos grupos e trabalho multigrupal. }\end{array}$ \\
\hline
\end{tabular}

Fonte: Adaptado de Bresser-Pereira (2005); Filippim e Rossetto (2006); Klering, Porsse e Guadagnin (2010); Paes de Paula (2005).

\section{Metodologia}

Quanto aos procedimentos metodológicos utilizou-se da pesquisa qualitativa, que segundo Flick (2005) este tipo de estudo é especialmente importante para o estudo de relações sociais. Como método de análise empírica recorreu-se ao estudo de caso, uma vez que o objetivo foi analisar o conteúdo do discurso dos atores sociais envolvidos na gestão de resíduos sólidos de um município mineiro de modo a verificar as relações existentes entre eles e relacioná-las com as abordagens da administração pública. Para a coleta de dados utilizou-se a aplicação de um roteiro semi-estruturado de entrevista que 
foram transcritas e relacionadas com as abordagens da administração pública. Para a realização das entrevistas foram elaborados roteiros constituídos por três grupos de perguntas (categorias): (I) sobre as relações estabelecidas entre os atores sociais; (2) sobre o funcionamento e o papel dos atores sociais na gestão dos resíduos sólidos do município em estudo; (3) sobre as práticas que caracterizam as abordagens da administração pública na gestão de resíduos sólidos. Foram entrevistados 48 atores sociais envolvidos na gestão de resíduos sólidos de um município de Minas Gerais. Os entrevistados foram categorizados em três setores: Setor Público (SPu), Setor Privado (SPr) e Terceiro Setor (TS), conforme agrupados na Figura I.

Além das entrevistas, foram coletados dados por meio das seguintes técnicas: pesquisa documental, observação e anotações de campo. Para a análise deste estudo utilizou-se a análise de conteúdo, proposta por Bardin (2009), que se refere a uma técnica para analisar as comunicações por meio de procedimentos sistemáticos e objetivos de descrição do conteúdo das mensagens.

Segundo Triviños (I995) a análise de conteúdo estrutura-se em: a) pré-análise, que corresponde aos processos de classificação, ordenação e leitura "flutuante" de todo o material coletado, visando obter um panorama geral e posteriormente os recortes e hipóteses de estudo; b) descrição analítica que a partir da delimitação do recorte a ser estudado realiza-se um aprofundamento, aplicando-se os procedimentos de codificação, classificação e categorização do material coletado por critérios de afinidades; c) interpretação que consiste na análise do material baseado na reflexão e intuição, relacionando o conteúdo explícito com o conteúdo implícito, ou seja, aquele que não é dito explicitado no texto, a fim de descobrir as ideologias, as tendências, ou fenômenos sociais expressos no material coletado.

Para a adequação da análise com o objetivo do estudo, foram selecionadas cinco categorias de análise: abordagem patrimonialista, abordagem burocrática, abordagem gerencial, abordagem societal e abordagem sistêmica. 
Quadro 2 - Classificação e Categorização dos Entrevistados

\begin{tabular}{|c|c|c|c|}
\hline Setor & Entrevistados & Cargo ou Representação & Entrevistados \\
\hline \multirow{14}{*}{$\begin{array}{l}\text { Setor } \\
\text { Público } \\
\text { (SPu) }\end{array}$} & \multirow{6}{*}{ Prefeitura } & Políticos: Prefeito, vice-prefeito, vereador & 3 \\
\hline & & Funcionários do setor de vigilância sanitária & 2 \\
\hline & & Funcionários do setor de infra-estrutura & 2 \\
\hline & & Funcionários da limpeza urbana e varrição & 2 \\
\hline & & Funcionário cedido para o CODEMA & 1 \\
\hline & & Funcionário destinado ao aterro & 1 \\
\hline & \multirow{5}{*}{ CODEMA } & Presidente & 1 \\
\hline & & Membro, representante da polícia ambiental & 1 \\
\hline & & Membros, funcionários da prefeitura & 2 \\
\hline & & Membro, funcionário do terceiro setor & 1 \\
\hline & & Membro, catador da Associação & 1 \\
\hline & Ministério Público & Promotor de justiça & 1 \\
\hline & \multirow{2}{*}{ Escolas } & Diretora e professora & 1 \\
\hline & & Professora & 1 \\
\hline \multicolumn{3}{|c|}{ Total de Entrevistados por Setor } & 20 \\
\hline \multirow{3}{*}{$\begin{array}{l}\text { Setor } \\
\text { Privado } \\
\text { (SPr) }\end{array}$} & \multirow[b]{3}{*}{ Iniciativa Privada } & Gerente de uma empresa que vende agrotóxico & 1 \\
\hline & & Repórter e Jornalista da TV do município & 1 \\
\hline & & $\begin{array}{l}\text { Empreendedores Autônomos: Artesão, sucateiro e } \\
\text { vendedor intermediário de recicláveis, proprietário do } \\
\text { hotel fazenda. }\end{array}$ & 4 \\
\hline \multicolumn{3}{|c|}{ Total de Entrevistados por Setor } & 6 \\
\hline \multirow{9}{*}{$\begin{array}{l}\text { Terceiro } \\
\text { Setor } \\
\text { (TS) }\end{array}$} & \multirow{4}{*}{$\begin{array}{c}\text { Associação de } \\
\text { Catadores }\end{array}$} & Presidente & 1 \\
\hline & & Fiscal & 1 \\
\hline & & Secretária & 1 \\
\hline & & Associados & 11 \\
\hline & \multirow{5}{*}{$\begin{array}{c}\text { Entidades Sociais e } \\
\text { Ambientais }\end{array}$} & Presidente e Diretora da APAE & 2 \\
\hline & & Diretoras de Creches & 2 \\
\hline & & Representante do Centro de Terceira Idade & 1 \\
\hline & & Representantes de ONG`s Ambientais & 2 \\
\hline & & Representante da Associação Ambiental & 1 \\
\hline \multicolumn{3}{|c|}{ Total de Entrevistados por Setor } & 22 \\
\hline \multicolumn{3}{|c|}{ Total de Entrevistados nesta Pesquisa } & 48 \\
\hline
\end{tabular}

Fonte: Dados da Pesquisa

\section{Análise dos Dados}

Análise de conteúdo dos discursos dos atores sociais

A gestão de resíduos sólidos compreende a identificação dos resíduos (tipos de resíduos gerados pela comunidade); o tipo de acondicionamento; o modo da coleta e transporte; a necessidade ou não do tratamento do resíduo; e a disposição final. Foram identificadas nos discursos dos atores sociais envolvidos na gestão de resíduos sólidos de um município mineiro as abordagens da administração pública patrimonialista, burocrática, gerencial, societal e sistêmica nas relações do poder público e sociedade.

Abordagem patrimonialista 
As entrevistas demonstraram resquícios do patrimonialismo nas relações do poder público. O clientelismo e nepotismo, citado por Bresser-Pereira (2005) como características do patrimonialismo, foram encontrados nos discurso, uma vez que as pessoas que se tornavam membro do CODEMA eram políticas e utilizavam o órgão para benefício próprio e de seus conhecidos:

O CODEMA numa certa época era mais político do que próprio CODEMA. Então quer dizer, se colocava lá... Um vereador que foi presidente do CODEMA, exvereador que foi presidente do CODEMA... Então ficava aquela rixa política, multava as pessoas que eram da oposição. O CODEMA é deliberativo; é um órgão auxiliar do cidadão junto às autoridades para resolver questões do meio ambiente. Mas isto, não era o que estava acontecendo, as pessoas que estavam lá não tinha competência, as pessoas favoreciam os seus conhecidos. (SPu).

Fica evidente em alguns discursos dos entrevistados, a presença do favoritismo. A própria aprovação da usina antiga e do aterro é questionada:

A usina antiga e o aterro foram aprovados e construídos perto de uma nascente. Como a FEAM aprovou? Com esse projeto a prefeitura arrecadava ICMS ecológico. A aprovação e construção da usina beneficiaram o prefeito e a administração passada. Mas agora, tem um processo judicial para reparar as irregularidades. (SPu).

Percebe-se no discurso de dez entrevistados que eles reconhecem como normal a centralização de decisões e poder na figura do prefeito. O prefeito é visto como indivíduo que pode mudar regras no momento que lhe convier. A idéia de obter privilégios e vantagens do poder público também é constatada no discurso: “Com um ponto de coleta de recicláveis no estabelecimento, o que vamos ganhar do prefeito? Isenção de imposto? Alguma vantagem? Afinal estamos cedendo o espaço para instalar o ponto de coleta”. (SPr).

As análises evidenciam que as velhas práticas do patrimonialismo ainda não sucumbiram. Mesmo diante o surgimento de outras abordagens, o patrimonialismo não deixou de existir, sendo encontrado na gestão de alguns municípios, como pode ser confirmado nas pesquisas realizadas por Rezende (2OII), Freitas Jr. (2009) e Araújo (2OII). Essa pesquisa confirma os vestígios da abordagem patrimonialista nas relações dos atores envolvidos na gestão de resíduos sólidos do município em estudo.

\section{Abordagem burocrática}


Foi encontrada na fala de quinze entrevistados a existência de uma abordagem burocrática nas relações do poder público com as organizações e sociedade. Nesses discursos os entrevistados percebem que os gestores públicos municipais estão centrados na obediência à lei e não a mercê de suas vontades.

Hoje nós não somos mais poderosos não, existe uma lei de responsabilidade fiscal que inibe e proíbe, que possui regras, põe o roteiro certo e que é correta. As pessoas, às vezes, questionam: Ah, o prefeito pode! Mas, não pode! Porque agora, existem regras! (SPu).

O legalismo, formalismo, controle e impessoalidade citado por Bresser-Pereira (2005) foram encontrados nos discursos. Percebe-se que existe uma exigência do cumprimento da lei mesmo que não gere o resultado mais participativo e social.

Fizeram um termo de ajustamento de conduta junto ao Ministério Público e a Associação dos Catadores é a responsável pela triagem dos resíduos que é recolhido. A prefeitura continua sendo responsável pelo aterro do lixo que não é aproveitado. Quando encerrar o prazo do termo de conduta, vai ser necessário fazer uma licitação. E aí que tá, será que a Associação dos Catadores consegue permanecer com o serviço? Eles irão fazer o quê se não vencerem a licitação? (TS).

Alguns dos entrevistados demonstraram que a eficiência se fará presente na gestão dos resíduos sólidos quando houver o cumprimento da lei. Os discursos apontaram a lei como um instrumento essencial no processo de gestão dos resíduos sólidos:

Tem um projeto que foi enviado para a câmara municipal que a assessoria jurídica está analisando que é justamente a questão da educação ambiental nas escolas e também da capacitação de alguns grupos para estarem distribuídos na comunidade para realizar a conscientização. Quando isso for transformado em lei, vamos ver a mudança. (SPu).

Um dos entrevistados relatou um fato que comprova que as disfunções da burocracia mencionada por Merton (I970) podem gerar a ineficiência da administração pública:

Eu estava voltando da minha fazenda à tarde quando vi um rapaz jogando resíduo de óleo na estrada. Eu abordei o sujeito e disse que ele não poderia fazer isto. Ele não deu à mínima. Então, anotei a placa do veículo dele e liguei para o CODEMA. O CODEMA me informou que só poderia tomar alguma atitude se eu registrasse um Boletim de Ocorrência (BO). Eu cheguei à cidade e tentei registrar o BO, mas na delegacia me disseram que eu teria que segurar o infrator no local para a polícia registrar o flagrante. Não deu em nada, tentei tomar uma atitude e foi uma burocracia danada. Fiquei indignado, pois, os órgãos competentes aconselham a denunciar, mas é tanta burocracia que não dá resultado. Às vezes, encontro na zona rural, pessoas fazendo um amontoado de lixo e colocando fogo próximo às 
pastagens... Mas, com tanta burocracia para denunciar, só vou avisar se o fogo espalhar pelas pastagens... (TS).

A pesquisa apresentou características do modelo burocrático nas relações do poder público para gerir os resíduos sólidos. Na percepção de quatorze entrevistados a abordagem burocrática é apontada como a mais adequada para a administração pública lidar com o gerenciamento dos resíduos sólidos. Um dos entrevistados, que reforça a existência da burocracia nas relações do poder público e sociedade, explicou que a disfunção da burocracia tem gerado um resultado de ineficiência para a gestão dos resíduos sólidos do município.

\section{Abordagem gerencial}

A abordagem gerencial também está presente no discurso dos entrevistados. Nove entrevistados apresentaram em seus discursos características da adoção do modelo gerencial para lidar com a gestão dos resíduos sólidos do município. Foram mencionados nos discursos aspectos que indicam que a administração pública municipal tem buscado uma maior valorização dos seus funcionários e uma tendência dos gestores públicos a serem mais inovadores, conforme mencionado por Osborne e Gaebler (I992). O entrevistado do terceiro setor (TS) destaca: "Os gestores públicos não podem enrolar, eles não podem adiar, eles precisam ter decisão, ser mais dinâmicos.” Outro entrevistado do setor público (SPu) explica:

O município deve valorizar o funcionário que trabalha na varrição e na coleta do lixo. Este funcionário público deve ser bem remunerado, respeitado para que tenha a autoestima valorizada. A prefeitura tinha a mentalidade de que para penalizar um funcionário era só colocar ele para trabalhar no lixo. Agora, isso mudou. (SPu).

As características mencionadas por Bresser-Pereira (2005) e Paes de Paula (2005) de uma abordagem gerencial, como por exemplo, uma maior descentralização, terceirização dos serviços e estratégias neoliberais foram encontradas em diversos discursos demonstrando a presença do modelo gerencial no gerenciamento dos resíduos sólidos do município: “A coleta, o matadouro e a varrição são terceirizados. Assim, são mais eficiente e mais ágil. É interessante aliviar a prefeitura, assim, a coisa pública funciona". (SPu). 
A prefeitura tinha as caçambas para recolher os entulhos de construções. Tinha muita manutenção. A administração passada resolveu vender as caçambas, leiloou as caçambas, desativou o caminhão que fazia esta coleta de entulho. E agora colocou a iniciativa privada para realizar este serviço, é uma espécie de disque entulho. Então, a caçamba, o caminhão para carregar a caçamba e os resíduos da construção é de responsabilidade da empresa particular. (SPr).

A abordagem gerencial possui um foco na gestão por resultados, na avaliação de desempenho e na qualidade dos serviços públicos. O entrevistado do setor público enfatiza tais aspectos em seu discurso:

O gerenciamento de resíduos sólidos no município deve priorizar qualidade. Estamos tentando recolher o lixo no tempo hábil; realizar os transportes e rotas da coleta de forma mais econômica. Os serviços que estão sendo feitos pela iniciativa privada devem ser monitorados. A prefeitura está aplicando um questionário para saber a satisfação dos cidadãos em relação aos serviços relacionados a coleta, varrição, tratamento e disposição final dos resíduos. (SPu).

A análise de discurso também possui evidências de uma abordagem gerencial nas relações do poder público e sociedade. Na percepção de nove entrevistados, o poder público demonstrou aberto a adotar práticas gerenciais provenientes do setor privado ou terceirizar serviços que considera ser mais bem desempenhado pela iniciativa privada.A abordagem gerencial possui um foco na gestão por resultados, na avaliação de desempenho e na qualidade dos serviços públicos. O entrevistado do setor público enfatiza tais aspectos em seu discurso:

\section{Abordagem societal}

O discurso dos entrevistados comprovou que existe a abordagem societal nas relações do poder público com os outros atores sociais no gerenciamento dos resíduos sólidos do município. Seis entrevistados mencionaram característica da abordagem societal nas relações da gestão dos resíduos sólidos. As características dizem respeito a uma participação popular na formulação e implementação das ações públicas; na valorização dos conselhos gestores de políticas públicas e fórum temático; e controle social (PAES DE PAULA, 2005). 
A forma mais participativa para a população administrar são os conselhos municipais, em todas as áreas: saúde, assistência social, educação, esporte e meio ambiente. São deliberações que faz com que o executivo tenha que cumprir. (SPr).

As pessoas têm participado de forma mais efetiva, é possível ver muita denúncia e reclamação. As pessoas fazem uma denúncia ambiental com muito mais tranqüilidade. Elas explicam o que está acontecendo, o dano que está causando e até as providências que devem ser tomadas. $(\mathrm{SPu})$.

A Associação de Catadores do município teve a sua origem no Fórum de Lixo Municipal. O poder público ao apresentar a problemática dos resíduos sólidos no Fórum Municipal de Lixo promoveu uma discussão. Assim, a população participou sugerindo uma associação de catadores. No próprio fórum existiam pessoas que tinham o interesse em fundar a associação. A associação foi fundada com um caráter autossustentável. No próprio discurso de um associado, percebe-se nas relações a abordagem societal: " $\mathrm{Na}$ Associação de catadores, ninguém é patrão de ninguém, aqui todo mundo sabe o que fazer. Se não fizer direito, é nosso dinheiro que está indo embora para o lixo.” (TS).

No discurso dos entrevistados foram encontradas características da abordagem societal nas relações do poder público e sociedade. Contudo, é uma abordagem que não é predominante.

Nós temos que incentivar a participação, de forma a incorporar o cidadão na administração. As pessoas estão cansadas do discurso. Se você programar uma palestra ou um discurso sobre o lixo, as pessoas vão dizer: Ah, isto eu já escutei! Isto é uma decisão só do prefeito! Então, precisamos envolver as pessoas nas decisões, mostrar que elas podem contribuir com as suas opiniões. (TS).

Os relatos comprovam que é uma essa abordagem é ainda incipiente na prática da administração brasileira, devido à cultura enraizada em aspectos patrimonialistas e de subserviência do cidadão ao Estado.

\section{Abordagem sistêmica}

A análise do discurso apresentou indícios de um "Estado em rede". Conforme descrito pelos autores Klering, Porsse e Guadagnin (2010) o "Estado em rede" representa a interação entre diversos atores em que o Estado exerce a posição de igualdade em relação aos mesmos. As redes definem os papéis a ser desempenhadas pelos atores, compartilham conhecimento e tecnologias criando uma sinergia de forma a 
solucionar problemas de domínio público. No discurso de oito entrevistados é possível identificar sinais e tendências da abordagem sistêmica nas relações do poder público e sociedade. No gerenciamento dos resíduos sólidos, pode ser destacado no discurso do entrevistado, que o município visa uma interação em redes: “Já pensamos em consórcio entre os municípios para fazer a gestão dos resíduos sólidos. Estamos tentando uma parceria com os municípios vizinhos”. (SPu).

Percebe-se nos discursos que o município já tem feito parcerias que envolvem diversos atores sociais (poder público, iniciativa privada e terceiro setor). No recolhimento dos vasilhames de agrotóxico, a prefeitura fez uma parceria com as cooperativas e iniciativa privada que vendem este tipo de produto. As empresas ficam responsáveis por recolher, existe um ponto de coleta no próprio estabelecimento. Além disso, a administração pública municipal junto com estas empresas é responsável em conscientizar o descarte de forma correta, por meio de palestras, cartilhas e outros.

A prefeitura está dando proteção ao descarte do lixo agrotóxico. A própria iniciativa privada que vende este tipo de produto é a responsável pelo recolhimento. A prefeitura ajuda a fazer a cartilha para conscientizar os produtores, fazendeiros e clientes que consomem estes produtos. (SPr).

Outro fato que demonstra a presença da abordagem sistêmica na gestão dos resíduos sólidos é a própria parceria e integração da Associação dos Catadores com a iniciativa privada e o poder público.

Tudo para funcionar tem que ter parceria. Se não fizer parceria não funciona. Tanto a Associação dos Catadores... Se a prefeitura não ajudar cedendo o lixo não tem como eles catarem o lixo, porque aí eles ficam só com a rua. Essa parceria com a prefeitura... A prefeitura cedeu o espaço e as esteiras que eles estão trabalhando. Para o CODEMA, a prefeitura cedeu salas também. (TS).

A prefeitura fez um termo de concessão cedendo o espaço, esteiras para os catadores realizarem a triagem dos resíduos. A iniciativa privada também disponibilizou pontos de coleta de materiais reciclados. Toda a semana os funcionários da prefeitura passam nos pontos de coleta com um caminhão recolhendo e entregam na Associação dos Catadores.

\section{Considerações Finais}


Os resultados explicitaram que nenhuma abordagem da administração pública apareceu nas relações na sua forma pura, apresentando-se combinada umas com as outras. Verificou-se que as relações do poder público e sociedade, no gerenciamento dos resíduos sólidos de um município de Minas Gerias, apresentaram evidências das abordagens patrimonialista, burocrática, gerencial, societal e sistêmica.

As relações possuem resquícios das práticas patrimonialistas, mostrando que ainda se faz uso da função pública para extrair benefícios particulares. A abordagem burocrática também foi encontrada, ao usar a legislação para o funcionamento da gestão de resíduos sólidos. A abordagem gerencial foi identificada, a administração pública tem buscado adotar práticas da iniciativa privada e terceirizar determinados serviços. A abordagem sistêmica ainda é incipiente no gerenciamento dos resíduos sólidos do município. No entanto, a abordagem sistêmica como a societal indicam ser uma tendência das relações do poder público e atores sociais no gerenciamento dos resíduos sólidos do município.

A pesquisa constatou que a presença de uma abordagem administrativa não exclui outra abordagem. Percebe-se um processo dinâmico, permanente, conflitivo e inacabado. Compreende-se que os atores sociais necessitam romper com relações patrimonialistas, ampliar espaços democráticos, não exagerar com procedimentos formais, fazer uso de práticas que condizem com a sua realidade e criar possibilidades de obter uma maior sinergia.

Esse estudo apresentou limitações, como por exemplo, a restrição dessa pesquisa em apenas um município e área. Nessa perspectiva, esse artigo aponta para a necessidade de realizar pesquisas empíricas sobre as relações entre poder público e sociedade em diversos municípios e áreas da administração pública, como na saúde e educação.

\section{Referências}

ACKROYD, S.; KIRKPATRICK, I.; WALKER, R. M. Public management reform in the UK and its consequences for professional organization: A comparative analysis. Public Administration, v. 85, n. I, p. 9-26, 2007 . 
ARAÚJO, P. G. de. Análise da aplicabilidade do modelo gerencial na administração pública. Dissertação (Mestrado em Administração) - Universidade Federal de Lavras (UFLA). Lavras, MG, 2 OII.

BARDIN, L. Análise de Conteúdo. Lisboa: Edições 7o, 2009.

BERRY, F. S., BROWER, R. S., CHOI, S. O. K., GOA, W. X., JANG, H., KWON, M., WORD, J. Three traditions of network research: what the public management research agenda can learn from other research communities. Public Administration Review, 64 (5), I-I4, 2004.

BRESSER-PEREIRA, L. C. Da administração pública burocrática à gerencial. In: L. C. BresserPereira \& P. K. Spink (Org.). Reforma do Estado e administração pública gerencial. Rio de Janeiro: Fundação Getúlio Vargas, p. 237-270, 2005.

CAPOBIANGO, R. P., NASCIMENTO, A. L., FARONI, W., SILVA, E. A. Reformas Administrativas no Brasil: Uma abordagem teórica e crítica. VI Encontro de Administração Pública e Governança, EnAPG, Vitória/ES, Brasil, novembro, 20Iо.

CARDOSO, F. H. Reforma do Estado. In: BRESSER-PEREIRA. L. C.; SPINK, P. K. (Org.). Reforma do Estado e administração pública gerencial. Rio de Janeiro: Fundação Getúlio Vargas, p. I5-I9, 2005 .

CASTELLS, M. Sociedade em rede. São Paulo: Paz e Terra, I999.

FAORO, R. Os donos do poder: formação do patronato político brasileiro. São Paulo: Globo, 2 OOI.

FILIPPIM, E. S., ROSSETTO, C. R. Visões norteadoras de administração pública para o desenvolvimento num contexto regional. IV Encontro de Administração Pública e Governança, EnAPG, São Paulo/SP, novembro, 2006.

FLICK, U. Métodos qualitativos na investigação científica. Lisboa: Monitor, 2005.

FREITAS JR, D. B. A avaliação da administração pública gerencial em municípios por meio de indicadores. Dissertação (Mestrado em Administração) - Universidade Federal de Lavras (UFLA). Lavras, MG, 2009.

HANSEN, M. B. Antecedents of Organizational Innovation: The Diffusion of New Public Management into Danish Local Government. Public Administration, v. 89, n. 2, p. 285-306, 20 II.

KLERING, L. R., PORSSE, M. C. S., GUADAGNIN, L. A. Novos caminhos da administração pública brasileira. Análise: Revista Científica de Administração, Contabilidade e Economia, v. 2I, n. I, p. 4-I7, 20Io. Disponível em: http://caioba.pucrs.br/ojs/index.php/face/article/view/823I/5903. Acesso em I7 nov. 2OII.

MARTINS, L. Reforma da administração pública e cultura política no Brasil: uma visão geral. Cadernos ENAP, v. 8, n. 6I, r997. Disponível em:

http://www.enap.gov.br/index.php?option=com_docman\&task=doc_download\&gid=I6I . Acesso em I3 dez. 2OII.

MERTON, R. K. Sociologia: teoria e estrutura. São Paulo: Mestre Jou, I97O.

MOYNIHAN, D. P. Managing for results in state government: Evaluating a decade of reform. Public Administration Review, v. 66, n. I, p. 77-89, Jan-Feb. 2006. 
NASCIMENTO, L. C., CKGNAZAROFF, I. B. Rede de política pública: estudo de caso no âmbito do Sistema Único de Saúde do Estado de Minas Gerais/SUS-MG. XXXI Encontro Nacional da Associação Nacional de Pós-graduação e Pesquisa em Administração, EnANPAD, Rio de Janeiro/RJ, setembro, 2007 .

OSBORNE, D., GAEBLER, T. Reinventando o Governo: como o espírito empreendedor está transformando o setor público. Brasília: Editora MH Comunicação, 1992.

PAES DE PAULA, A. P. Por uma nova gestão pública: limites e potencialidades da experiência contemporânea. Rio de Janeiro: Fundação Getúlio Vargas, 2005.

PINA, V; TORRES, L; ACERETE, B. Are ICTs promoting government accountability?: A comparative analysis of e-governance developments in I9 OECD countries. Critical Perspectives on Accounting, v.I8, n.5, p. 583-602, 2007 .

REZENDE, J. B. Administração pública em municípios de pequeno porte do sul de Minas Gerais: velhas questões, modernas leis e práticas patrimonialistas. Tese (Doutorado em Administração) Universidade Federal de Lavras (UFLA). Lavras, MG, 2 OII.

SKARICA, M. Public Administration Reform in a Fragile Institutional Framework: The Case of Albania. Hrvatska I Komparativna Javna uprava, p. 36I-389, $20 \mathrm{I2}$.

SNIJKERS, K. E-Government, intergovernmental relations and the citizen. European Group of Public Administration, p. I-2, 2005 .

TENÓRIO, F. G. O mito da participação. Revista de Administração Pública, v. 24, n. 3, p.I62-I64, I990.

TENÓRIO, F. G., ROZENBERG, J. E. Gestão pública e cidadania: metodologias participativas em ação. Revista de Administração Pública, v. 3I, n. 4, p. IOI-I25, I997.

TRIVIÑOS, A. N. S. Introdução à pesquisa em Cièncias Sociais: a pesquisa qualitativa em educação. São Paulo: Atlas, I995.

WEBER, M. Economia y sociedade: esbozo de sociologia comprensiva. $2^{\text {a }}$ Ed. México: Fondo de Cultura Econômica, 2005. 